\title{
Acute hemorrhagic conjunctivitis: anti-coxsackievirus A24 variant secretory immunoglobulin $A$ in acute and convalescent tear
}

This article was published in the following Dove Press journal:

Clinical Ophthalmology

10 September 2015

Number of times this article has been viewed

\section{Marlyn P Langford \\ Edwin A Anders \\ Maxwell A Burch}

Department of Ophthalmology, Louisiana State University Health Sciences Center, Shreveport, LA, USA
Correspondence: Marlyn P Langford Department of Ophthalmology, Louisiana State University Health Sciences Center, I50I Kings Highway, PO Box 33932, Shreveport, LA 7II30, USA

$\mathrm{Tel}+\mathrm{I} 3186755018$

Fax + I 3186756000

Email mlangf@Isuhsc.edu
Purpose: The purpose of this paper is to present the clinical course of a laboratory-acquired case of acute hemorrhagic conjunctivitis (AHC) caused by coxsackievirus A24 variant (CA24v). Also, the anti-CA24v neutralizing activity and anti-CA24v immunoglobulin ( $\mathrm{Ig}$ ) G and secretory $\operatorname{Ig} \mathrm{A}(\mathrm{SIgA})$ in acute and convalescent tears and/or sera are presented.

Case: A 60-year-old male presented with acute-onset left eyelid edema, tearing, conjunctival erythema, pain, foreign body sensation, and subconjunctival hemorrhage 24 hours after suspected laboratory exposure. Bilateral conjunctivitis presented 24 hours later and resolved in 10 days. Methods: Tear and blood samples were collected for virus isolation and neutralizing assays. CA24v-reactive IgG and SIgA in tear and/or serum samples were detected by immunofluorescent antibody analysis of ethanol-fixed virus-infected cells.

Results: Peak tear neutralization titers $(1,000-1,500 \mathrm{U} / \mathrm{mL})$ against the isolated virus occurred 1 day post-onset (po) of AHC. Tear neutralization titers became undetectable by the sixth day as serum neutralization titers became detectable on the ninth day po $(60 \mathrm{U} / \mathrm{mL})$, peaked by 21 days $(3,000 \mathrm{U} / \mathrm{mL})$, declined by 1 year to $200 \mathrm{U} / \mathrm{mL}$, and remained at $30 \mathrm{U} / \mathrm{mL} 5$ years po. Antibody to human IgG, IgA, and secretory component (sIgA) reacted with CA24v-infected cells treated with pooled acute tears collected 1-4 days po. Predominantly, sIgA was detected in CA24v-infected cells treated with tears collected 4 years and 5 years post-AHC, while convalescent serum contained predominantly anti-CA24v IgG.

Conclusion: AHC was confirmed by CA24v isolation, tear anti-CA24v neutralizing activity, and seroconversion. The detection of CA24v-reactive $\operatorname{IgG}, \mathrm{sIgA}$, and neutralizing activity in tears collected 1-4 days po of AHC supports plasma extravasation of IgG and suggests a defensive role for tear anti-CA24v sIgA. The results suggest that immunofluorescent antibody analysis of tears for persistent anti-CA24v sIgA may be useful in epidemiological monitoring of AHC.

Keywords: neutralization, immunofluorescence, eye infection, enterovirus, seroconversion

\section{Introduction}

Epidemics of acute hemorrhagic conjunctivitis (AHC) have occurred worldwide since the first cases were reported in Accra, Ghana, and Singapore in 1969-1970. ${ }^{1,2}$ Two picornaviruses, enterovirus 70 (EV70) and coxsackievirus A24 variant (CA24v), were isolated and shown to be the etiologic agents of AHC epidemics. ${ }^{2-4} \mathrm{AHC}$ is highly contagious and is transmitted primarily by hand-to-eye-to-hand contact, but fomite and airborne spread is suspected. High attack rates in families and communities are common. High humidity, poor sanitation, overcrowded housing, and school/ factory exposure facilitate spread during epidemics. AHC is endemic in several countries where sporadic cases occur annually and local outbreaks and epidemics 
occur at 3-year to 5-year intervals. Pandemics of AHC involving millions of people have occurred at 8-year to 10 -year intervals in tropical and subtropical countries of the eastern and western hemispheres over the past 45 years and 35 years, respectively. ${ }^{5-10}$ EV70 AHC epidemics have not been reported in the past 5 years, but major CA24v AHC epidemics were reported in the Brazil, French Mayotte Island, Egypt, Uganda/Sudan, India, Indian Ocean islands, Japan, Thailand, and the Zhejiang and Shandong Provinces of the People's Republic of China. ${ }^{1-20}$ Home remedies are discouraged and are usually deleterious. ${ }^{5,6}$ Measures that prevent spread are employed to limit epidemics, hysteria, and economic losses, ${ }^{5,8,21}$ since no approved antiviral drugs or vaccines are currently available.

AHC symptoms include rapid onset, profuse tearing, itching/foreign body sensation, pain, erythema, lid edema, vascular dilation of conjunctival blood vessels, with or without chemosis, and subconjunctival hemorrhage that usually subsides steadily after the third day and completely resolves by 10-14 days. ${ }^{1,6,10}$ The conjunctivitis is caused by virus-induced effects on conjunctival, corneal, and vascular endothelial cells. ${ }^{8,22}$ Ocular host defenses against EV70 and $\mathrm{CA} 24 \mathrm{v}$ infection include profuse tearing and conjunctival inflammation with local production of interferon (IFN) and virus-specific neutralizing activity. ${ }^{23-26}$ These ocular host defenses likely act together to rapidly clear the IFN-sensitive enteroviruses and limit ocular symptoms ${ }^{27-29}$ but do not prevent secondary CA24v infection of the upper respiratory tract $^{7}$ or EV70 neuropathy observed more commonly in males. ${ }^{30}$

The factors promoting sporadic and recurrent AHC epidemics are unknown but likely include unrestricted travel, ${ }^{5,31}$ antigenic/genetic divergence of AHC viruses, ${ }^{32-34}$ subclinical infection, ${ }^{35,36}$ and the absence or waning of population immunity. ${ }^{3,37-39}$ An additional confounding factor is the low frequency of seroconversion $(15 \%-60 \%)$ reported in many AHC epidemics, suggesting that the ocular infection may not provide protection. ${ }^{3,37-41}$ The weak systemic immune response to AHC is likely due to the highly localized nature of the infection to the eye (mucosal epithelium) and rapid viral reduction, but hyporesponsiveness or local antibody production exclusively has not been ruled out. ${ }^{42,43}$ Paradoxically, it has been reported that high pre-epidemic serum antibody titers provide sex-specific protection against EV70 AHC. ${ }^{44}$ Generally, subclinical infection is monitored between epidemics by detection of AHC virus and/or seropositive individuals, while the population's relative susceptibility to an AHC epidemic is predicated upon the absence of, or decline in, serum antibody to the AHC viruses. $3,32,33,37-41,44-46$
The persistence of antibody to AHC viruses in tear postinfection is unknown.

We presented the clinical course of an AHC case through 6 days, demonstrated the acute increase in anti-CA24v neutralizing activity and secretory immunoglobulin (Ig) A ( $\operatorname{sgA})$ in acute tears, and used immunofluorescence antibody analysis to show the persistence of CA24v-reactive sIgA in tears collected 4-5 years post-AHC. The detection of antiCA24v sIgA in acute tears suggested local production and a defensive role against infection.

\section{Case report}

A 60-year-old male presented with foreign body sensation in the left eye and symptoms of conjunctivitis (Figure 1) $\sim 24$ hours after possible laboratory exposure to AHC virus. His physical exam was within normal limits, and he reported no prior ocular infections, current systemic disease, or medication use. An external ocular examination of the left eye revealed lid edema, tearing, conjunctival erythema, dilated conjunctival blood vessels predominantly in the inferior temporal and nasal bulbar conjunctiva, and small blotches of subconjunctival hemorrhage in the inferior bulbar conjunctiva of the left eye (Figure 1A) that progressed through the day (Figure 1B). The onset of conjunctivitis in the right eye occurred in the evening/night of the second day 36-48 hours (Figure 1C). The right eye conjunctivitis mirrored that of the left eye, with onset of symptoms over 6 hours. The severity of signs and symptoms peaked in the left eye on day 2 and in the right eye on day 3 post-onset (po). The bilateral tearing, conjunctival erythema, and swelling increased through 24 hours, remained through 48 hours, and diminished by day 6 (Figure $1 \mathrm{C}$ and $\mathrm{F}$ ). The right eye signs and symptoms were generally less intense than in the left eye with the noted exception of a transient chemosis involving the infra-nasal bulbar conjunctival on day 3 that resolved in 24 hours (Figure 1D). No keratitis, iritis, purulent discharge, lymphadenopathy, fever, headache, malaise, or respiratory tract symptoms ${ }^{7}$ were noted, and the bilateral conjunctivitis resolved completely in 10 days without sequelae or treatment. No ocular infections were noted during the following 5 years, but the patient reported a short 3-week course of shingles localized to the right mid-crown dermatome 3 years post-AHC.

\section{Materials and methods Tears and sera}

Bilateral tear fluid samples $(200 \mu \mathrm{L})$ for virus isolation, neutralization, and immunoreactive antibody studies were 
A

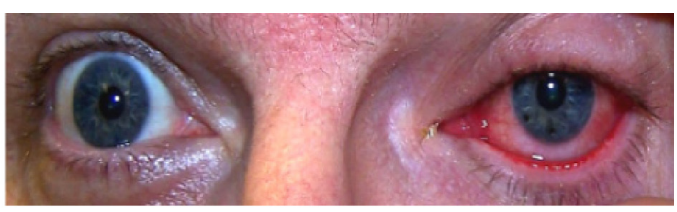

B

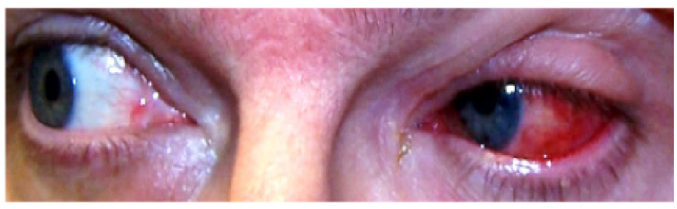

C

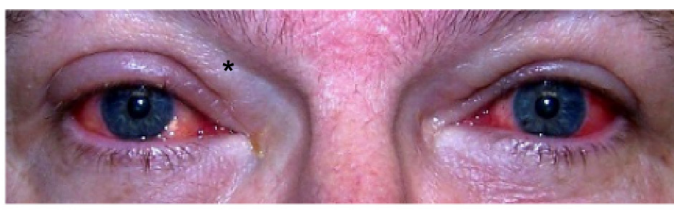

D

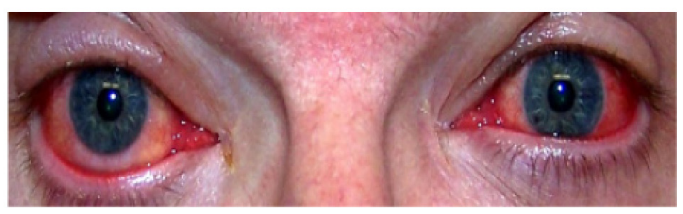

E

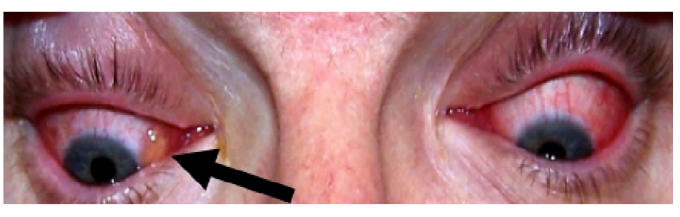

$\mathbf{F}$

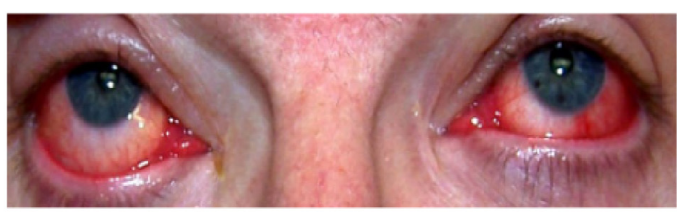

G

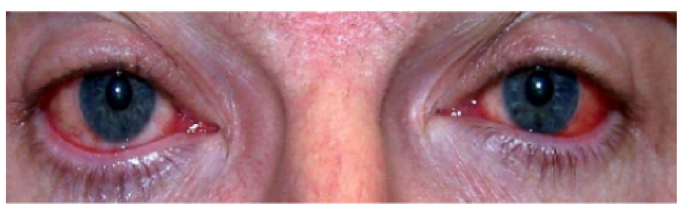

Figure I Clinical presentation of bilateral ocular CA24v infection.

Notes: (A) First day morning; (B) first day afternoon; (C) second day am; (D) second day pm; (E) third day am; (F) fourth day pm; (G) sixth day pm. The bilateral lid edema $(*)$, vascular dilation, and conjunctival erythema were noted on the second day, and the inferior-nasal chemosis (arrow) was present on the third day post$\mathrm{AHC}$. The clinical signs were less and resolved more quickly in the right (second infected) than the left (first affected) eye.

Abbreviations: $\mathrm{CA} 24 \mathrm{v}$, coxsackievirus A24; $\mathrm{AHC}$, acute hemorrhagic conjunctivitis.

collected one to two times daily in glass capillary pipettes 1-6 days po, and pooled bilateral tear samples $(150 \mu \mathrm{L})$ were collected on 2 consecutive days at $\sim 1$ year, 4 years, and 5 years po as previously reported. ${ }^{23,25}$ Venous blood samples $(1-3 \mathrm{~mL})$ were collected at intervals between 2 days and 60 days, and at 4 months, 1 year, 4 years, and 5 years po using a $25-\mathrm{G}$ infusion set with syringe and standard aseptic phlebotomy methods. Clarified tears and sera from clotted blood samples were collected after desktop centrifugation $\left(1,000 \times g\right.$ for 5 minutes) and were stored frozen $\left(-10^{\circ} \mathrm{C}\right)$. Reference antisera obtained from the National Institutes of Health, Bethesda, MD, USA (NIH Research Reference Reagents) included antisera to CA24 (Joseph) (CA24/Africa/ Joseph/1952; V027-501-563) and polioviruses type 1 (LSC; V001-511-560), type 2 (P-712; V002-511-560), and type 3 (Leon; V003-5110560). Antiserum to prototype CA24v (Singapore/EH24/1970) was provided by Dr M Yin-Murphy, Singapore University, Singapore. Antiserum to prototype EV70 (Japan/670/1971) was obtained from Reisaku Kono, National Institute of Health, Tokyo, Japan. This case report was reviewed and approved by the LSU Health Institutional Review Board, and the clinical investigations were conducted in accordance with the World Health Organization Declaration of Helsinki.

\section{Cell culture}

Human retinal pigmented epithelial (HRPE) cells (CRL2502; ARPE-19) and African green monkey kidney (AGMK) cells were maintained as recommended by the provider; (American Type Culture Collection, Rockville, MD, USA). (It should be noted that cultured retinal pigmented epithelial cells express $\gamma \mathrm{Fc}$ receptor mRNA ${ }^{47}$ ) For experiments, trypsinized cells were suspended $\left(5 \times 10^{6}\right.$ cells $\left./ \mathrm{mL}\right)$ in Dulbecco's minimal essential medium (DMEM; SigmaAldrich, St Louis, MO, USA) supplemented with 2\% bovine calf serum (HyClone Laboratories, Logan, UT, USA) and antibiotics (100 U penicillin and $100 \mu \mathrm{g}$ streptomycin $/ \mathrm{mL}$; Thermo Fisher Scientific, Waltham, MA, USA). Cell suspensions in DMEM were pipetted into six-well dish cultures ( 2 mL/well; Sarstedt AG \& Co., Nümbrecht, Germany) for virus isolation and propagation, 96-well microtiter plate cultures $(100 \mu \mathrm{L} /$ well; Sarstedt AG \& Co.) for neutralization assays, and Lab-Tek ${ }^{\circledR}$ eight-chamber glass slide culture (200 $\mu \mathrm{L} /$ well; Thermo Fischer Scientific, Rochester, NY, USA) for immunofluorescent antibody (IFA) analysis. The cultures were incubated for 24 hours at $37^{\circ} \mathrm{C}$ in a $5 \%$ $\mathrm{CO}_{2}$-humidified atmosphere in a water-jacketed incubator (Forma-Scientific, Fredrick, MD, USA) until cell monolayers reached confluence.

\section{Virus isolation and viruses}

Tear fluid was applied directly to fresh medium over HRPE or AGMK cells and incubated at $37^{\circ} \mathrm{C}$ as previously 
reported. ${ }^{23}$ Viral cytopathogenic effects in tear-inoculated cultures approached $100 \%$ after 24 -hour to 48-hour incubation, and the culture media was harvested. Early-passage HRPE cell virus isolate sub-stocks were clarified $(5,000 \times g$ for 10 minutes), aliquoted, and stored frozen $\left(-80^{\circ} \mathrm{C}\right)$. Prototype (Singapore/SEC24/1970) ${ }^{2}$ and prime type CA24v Texas/MO7/1977, ${ }^{23}$ prototype and prime EV70 types (Japan/ J670/1971 and Florida/KW97/1981, respectively), ${ }^{48}$ and/or poliovirus type 1 (Mahoney) were grown in HRPE cells and used in HRPE cell neutralization assays.

\section{Neutralization assay}

The neutralizing titers were determined from duplicate micro-neutralization assays in HRPE cells as previously described. ${ }^{23,25}$ Briefly, half- $\log _{10}$ dilutions of tear and serum samples, as well as reference antisera, were reacted with 20-50 plaque-forming units (PFU) of Louisiana/LTV/2010, isolates of CA24v and EV70, and poliovirus serotypes. The reciprocal of the mean endpoint dilution yielding 50\% reduction in virus plaques was used as the neutralization titer (units per milliliter).

\section{IFA assay}

For all immunofluorescence experiments, HRPE and AGMK cells were grown on multiple Lab-Tek ${ }^{\circledR}$ eight-chamber slides (Thermo Fischer Scientific), infected with 20-50 PFU of Louisiana/LTV/2010/culture and incubated at $37^{\circ} \mathrm{C}$ until plaques formed (usually 24 hours). The culture fluid was removed, and the cells were fixed with cold $70 \%$ ethanol $\left(-10^{\circ} \mathrm{C}\right)$ for 30 minutes. The ethanol was removed, and the cells were washed three times with phosphate-buffered saline (PBS; $\mathrm{pH}$ 7.4). The cells were washed with PBS, and the nuclei were stained with 4',6-diamino-2-phenylindole (DAPI) as previously described. ${ }^{49}$ The DAPI stain was removed, and the cells were rinsed twice with PBS. Rabbit serum (1:100 dilution in PBS) was applied to block nonspecific binding and removed after 30-minute incubation at room temperature. Side-by-side duplicate slide culture wells on two slides were overlaid with $200 \mu \mathrm{L}$ of a 1:30 dilution of pooled acute tears (collected 1-4 days po), 4-year or 5-year convalescent tears, or 1:100 dilution of an acute and convalescent serum in PBS. The tear and sera dilutions were removed after overnight incubation at $4^{\circ} \mathrm{C}$, and the cells were washed three times with PBS. For dual IFA staining, $200 \mu \mathrm{L}$ of PBS containing a 1:1,000 dilution of fluorescein isothiocyanate (FITC)-labeled goat antihuman IgG (Fc-chain specific) and tetramethylrhodamine isothiocyanate (TRITC)-conjugated goat antihuman serum
IgA (Fc specific; Jackson ImmunoResearch Laboratories, Inc., West Grove, PA, USA) (diluted 1:1,000 in PBS) were added to duplicate slide culture chambers and incubated for 3 hours at room temperature in the dark. After removal of the secondary antibodies, the slides were rinsed six times with PBS, excess PBS was blotted off, and glass cover slips with mounting media were applied. To detect sIgA in acute and (4-year or 5-year) convalescent tears, a 1:1,000 dilution of goat antihuman secretory component (bound and free) (Sigma-Aldrich) in PBS was applied to tear-treated duplicate slide cultures for 6 hours at room temperature. Goat antibody to secretory component in tear-treated, virus-infected cells was detected by removing the tear/ PBS, rinsing three times with fresh PBS, and applying a 1:1,000 dilution of TRITC-conjugated donkey anti-goat IgG (Jackson ImmunoResearch Laboratories, Inc.) in PBS and incubated at room temperature for 3 hours. After removal of fluorochrome-labeled secondary antibody, the slides were rinsed six times with PBS, excess PBS was blotted off, and glass cover slips with mounting media were applied. All IFA procedures and digital color images were generated as previously described. ${ }^{49}$ Red, green, and blue images were merged using Scanalytics IPLab 3.7 software.

\section{Results}

\section{Virus isolation and serotyping}

Cytopathogenicity consistent with enteroviral infection was detected in HRPE cell cultures 24 hours postinoculation with pooled bilateral tear samples (not shown). The isolated virus was designated Louisiana/LTV/2010 and was neutralized by rabbit antiserum raised against prototype CA24v $(300 \mathrm{U} / \mathrm{mL})$ but not by antisera to EV70, CA24 (Africa/Joseph/1952), or poliovirus types 1,2 , and 3 (not shown).

\section{Tear neutralizing activity}

Bilateral tear samples contained neutralizing activity against Louisiana/LTV/2010 (Figure 2). Neutralizing activity against the isolated virus was detected in left eye tears on the first day po but was not detected in tears from the fellow unaffected eye. Peak titers of tear neutralizing activity were detected in tears of the left $(1,000 \mathrm{U} / \mathrm{mL})$ and right $(1,500 \mathrm{U} / \mathrm{mL})$ eyes on days 1 and 2 po of AHC, respectively. Tear anti-CA24v neutralizing activity declined to near-undetectable levels bilaterally by day 6 and remained undetectable at 5 years. Concomitantly, neutralizing activity was detected in pooled 1-day to 4-day tears against prototype CA24v (300 U/mL) and poliovirus type $1(20 \mathrm{U} / \mathrm{mL})$ but not EV70 $(<10 \mathrm{U} / \mathrm{mL})$ (not graphed). 


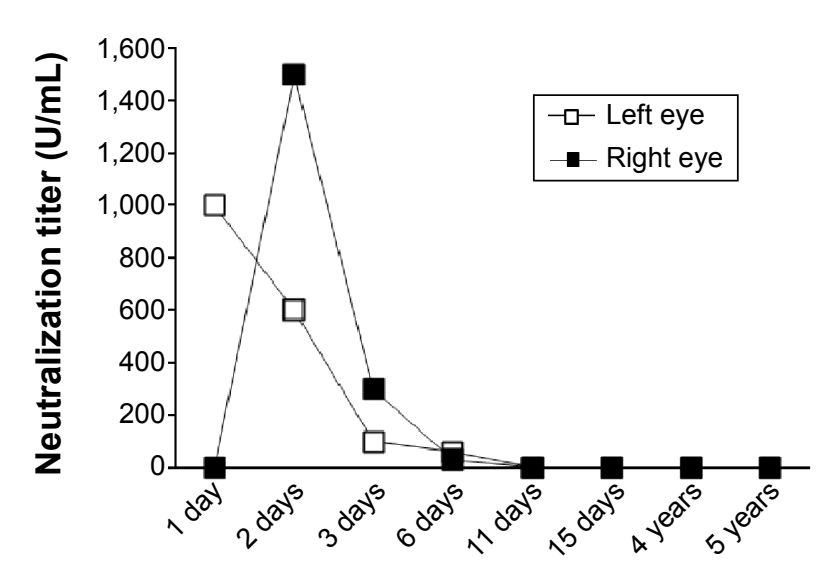

Time post-AHC onset

Figure 2 Anti-CA24v neutralizing titers in acute tears post-AHC onset. Abbreviations: CA24v, coxsackievirus A24 variant; AHC, acute hemorrhagic conjunctivitis.

\section{Serum neutralizing antibody response}

A greater than fourfold increase in the serum neutralizing antibody titer against the Louisiana/LTV/2010 isolate was detected between days 2 and $9(<10-60 \mathrm{U} / \mathrm{mL})$. The serum neutralization antibody titer peaked at $3,000 \mathrm{U} / \mathrm{mL}$ on day 21 and declined from $2,000 \mathrm{U} / \mathrm{mL}$ at 4 months to $30 \mathrm{U} / \mathrm{mL}$ by 5 years (Figure 3 ). Serum neutralization titers against prototype CA24v Singapore/SEC24/1970 (<10-600 U/mL) and prime type Texas/MO7/1977 $(<10-3,000 \mathrm{U} / \mathrm{mL})$ paralleled those of the tear virus isolate. Anti-EV70 (Tokyo/J670/1971 and Florida/KW97/1981) neutralization was not detected in acute or convalescent serum $(<10 \mathrm{U} / \mathrm{mL})$, but anti-poliovirus

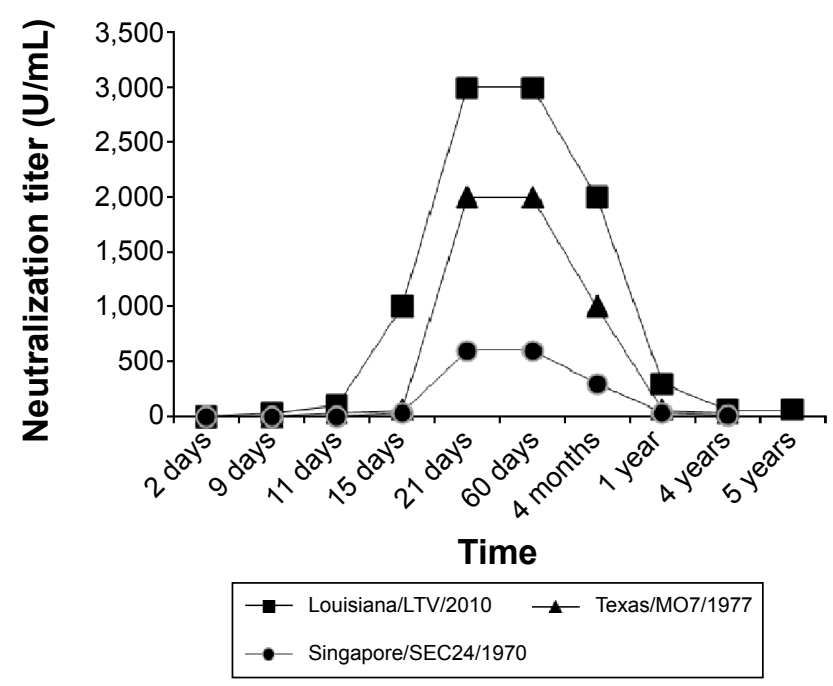

Figure 3 Anti-CA24v serum antibody response.

Notes: Serum neutralization titer against CA24v isolates; Louisiana/LTV/2010, Texas/MO7/1977, and prototype Singapore/SEC24/1970.

Abbreviation: CA24v, coxsackievirus A24 variant. type 1 (Mahoney) neutralizing antibody activity was detected in acute and convalescent sera (60-200 U/mL) (not graphed). Note that the sera neutralization titer was lower against the prototype CA24v Singapore/SEC24/1970 than the prime type CA24v Texas/MO7/1977 and the isolated virus, Louisiana/ LTV/2010. Taken together, the results suggest that the isolated virus was antigenically similar to prototype and prime type CA24v.

\section{Detection of anti-CA24v IgA and IgG in tear and serum by IFA}

Anti-CA24v-reactive IgG and IgA were detected in ethanolfixed, virus-infected HRPE and AGMK cells treated with pooled acute tears collected on 1-4 days and at 4 years or 5 years post-AHC as well as acute ( 11 days) and convalescent (5 years) sera (Figure 4). IgG and IgA in the pooled acute tears reacted with viral antigens in virus isolate-infected HRPE (Figure 4A) and AGMK cells (Figure 4B). Notably, some virus-infected cells were labeled with predominantly IgA or IgG. In some dual IgG- and IgA-labeled virus-infected cells, the IgA was generally localized to the cytoplasm (Figure 4A and B). Predominantly IgA, with little IgG, was detected in CA24v-infected cells treated with 4-year convalescent tears sample in HRPE cells (Figure 4C) or 5-year convalescent tear sample in AGMK cells (Figure 4D). Moreover, secretory component (indicative of $\operatorname{sigA}$ ) was detected in isolate-infected HRPE cells treated with pooled acute tears (Figure 4E) as well as 5-year convalescent tear (Figure 4F). In comparison, predominantly IgG labeling was detected in the isolate-infected cells treated with convalescent sera collected on 11 days (Figure 4G) and 5 years (Figure 4H). The results point to a predominance of anti-CA24v sIgA in convalescent tears and a predominance of anti-CA24v IgG in convalescent serum.

\section{Discussion}

The diagnosis of AHC was based upon history of recent $\mathrm{AHC}$ virus contact, short incubation period, acute onset of unilateral conjunctivitis with subconjunctival hemorrhage that spreads to the fellow eye within 48 hours, and complete resolution in 10 days. ${ }^{9}$ As in our case, the diagnosis of AHC is relatively simple for epidemic and laboratory-acquired infections. The etiological agent of the AHC was confirmed by isolation of a serotypic CA24v and demonstration of a fourfold increase in anti-CA24v neutralization titer between acute and convalescent serum samples. Further confirmation was CA24v-specific neutralizing activity in tears collected on $1-6$ days..$^{23,25,26}$ 

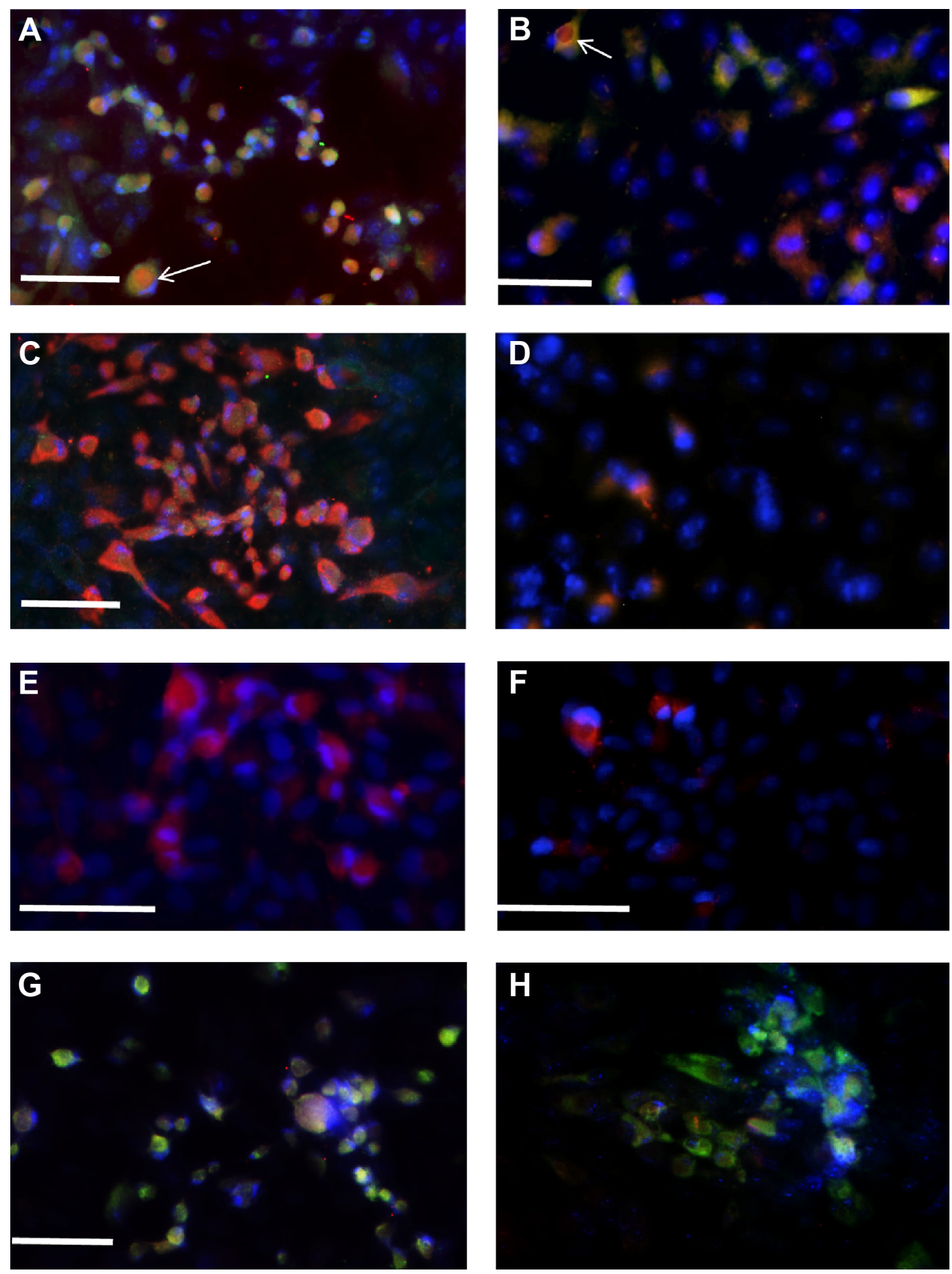

Figure 4 Immunoreactivity of tear and serum $\operatorname{lgG}$ (green) and IgA (red) from the AHC patient with CA24v-infected cells.

Notes: Arrows show similar differential staining patterns for tear $\lg G$ and $\lg A$ in CA24v infected HRPE and AGMK cells. (A) Detection of immunoreactive human IgG and/or IgA in CA24v-infected HRPE cells treated with pooled acute tears (collected I-4 days po). (B) Detection of immunoreactive human IgG and/or IgA in CA24v-infected AGMK cells treated with pooled acute tears. (C) Detection of immunoreactive human IgG and IgA in CA24v-infected HRPE cells treated with tears collected 4 years post-AHC. (D) Detection of immunoreactive human IgG and IgA in CA24v-infected AGMK cells treated with tears collected 5 years post-AHC. (E) Detection of antibody to secretory component (polymeric $\operatorname{lgA}$ ) in CA24v-infected HRPE cells treated with pooled acute tears. (F) Detection of antibody to secretory component (polymeric IgA) in CA24v-infected HRPE cells treated with tears collected 5 years post-AHC. (G) Detection of CA24v immunoreactive human IgG and IgA in acute serum (collected II days po)-treated virus-infected HRPE cells. (H) Detection of CA24v immunoreactive human IgG and IgA in virus-infected HRPE cells treated with the patient's convalescent serum (collected 5 years post-AHC). Bar $=50 \mu \mathrm{m}$. Abbreviations: IgG, immunoglobulin G; IgA, immunoglobulin A; AHC, acute hemorrhagic conjunctivitis; CA24v, coxsackievirus A24 variant; HRPE, human retinal pigmented epithelial; po, post-onset; AGMK, African green monkey kidney. 
The detection of anti-CA24v, but not anti-EV70, neutralizing activity with anti-CA24v IgG and $\operatorname{sgA}$ in AHC tears collected through 6 days is consistent with the idea that inflammation, and innate and humoral immune responses act together to inhibit the virus infection. ${ }^{23-29}$ The detection of the neutralizing activity in early tears is consistent with Ig activity and the previously reported detection of serum protein and Igs in 1-day to 3-day tears of epidemic AHC cases..$^{50}$ The IFA detection of non-neutralizing anti-CA24v IgG in acute serum and anti-CA24v IgG in tear suggests serum IgG extravasation due to inflammation-induced increased vascular permeability. Extravasation of serum IgG into the tear is also supported by the detection of anti-poliovirus neutralizing activity $(20 \mathrm{U} / \mathrm{mL})$ in pooled acute tears. The concomitant IFA detection of IgA (and secretory component) in CA24vinfected cells treated with pooled acute tears in the face of very low serum levels of anti-CA24v IgA suggests local ocular production of IgA..$^{51,52}$ Moreover, the anti-CA24v sIgA was detectable by IFA in tears at 5 years post-AHC. Interestingly, the detection of anti-CA24v sIgA with neutralizing activity in acute, but not in convalescent, tears suggests that the local ocular response shares similarities with the systemic responses reported for rubella, measles, and varicella-zoster viruses, in that virus-specific IgA first appears as neutralizing IgA and later becomes, or is replaced by, non-neutralizing $\operatorname{IgA} .{ }^{53}$ The detection of anti-CA24v $\operatorname{sIgA}$ and neutralizing activity in acute tears suggests that SIgA may neutralize extracellular virus and/or block virus entry. This idea is consistent with the emerging concept that polymeric IgA antibody may be taken into the cell during virus infection where it triggers intracellular virus neutralization and innate immune signaling. ${ }^{51,54,55}$ Alternatively, the possibility that cross-reactive neutralizing antibody ${ }^{56}$ or co-binding of $\operatorname{IgG}$ and $\operatorname{IgA}$ to CA24v may account for the early neutralizing activity in acute tear cannot be ruled out. Additional investigations are needed to determine if the early tear neutralizing activity is due to SIgA neutralization of $\mathrm{CA} 24 \mathrm{v}$ and whether convalescent tear anti$\mathrm{CA} 24 \mathrm{v}$ sIgA protects against infection.

The levels and patterns of tears IgG and IgA labeling of CA24v-infected cells differed from that of serum. There is a possibility that polyclonal human IgG and IgA react with different viral epitopes/antigens. (Note: tear and serum IgG and IgA bound to virus antigens were probed simultaneously.) That is, virus-infected cells treated with pooled acute tear exhibited IgG and/or IgA labeling, with some dual labeled cells exhibiting dense cytoplasmic IgA with peripheral IgG (Figure 4A and B). In contrast, virus-infected cells treated with convalescent ( 4 years or 5 years) tears exhibited predominantly cytoplasmic sIgA labeling. The strong IgA and weak IgG signals within CA24v-infected HRPE cells treated with convalescent tear collected 4 years po may be due to a higher concentration of IgA in normal tears, ${ }^{57}$ while the lower IgA signal in 5-year convalescent tear-treated cells could represent a reduction in the anti-CA24v IgA. Moreover, the anti-CA24v sIgA signal in virus-infected cells treated with convalescent tear supports the persistence of CA24v-specific IgA years after infection. ${ }^{58}$ Concomitantly, the anti-CA24v IgG IFA signal and neutralizing antibody activity in convalescent serum at 5 years post-AHC supports the persistence of anti-CA24v IgG.

\section{Conclusion}

In summary, the acute onset, signs and symptoms, and bilateral course in a previously seronegative laboratory employee were consistent with AHC epidemic case ${ }^{1,6,10}$ and previously reported laboratory-acquired AHC virus infections. ${ }^{23,59}$ The results of the tear and serum analysis support the rapid appearance of anti-CA24v IgG, sIgA, and neutralizing activity in tears prior to the serum antibody response. The anti-CA24v sIgA in pooled acute tears suggests that it may play a role in limiting the $\mathrm{CA} 24 \mathrm{v}$ infection. The persistence of anti-CA24v sIgA in tear up to 5 years suggests that it may have value in monitoring population immunity to $\mathrm{CA} 24 \mathrm{v}$ AHC. Tear collection is tolerated well and provides useful diagnostic, epidemiological, and immunological information. Finally, the occurrence of this inadvertent laboratory infection underscores the necessity for strict conformity to standard aseptic techniques and pre- and post-use decontamination of shared work areas and equipment to eliminate AHC virus infection of laboratory personnel.

\section{Acknowledgments}

The authors thank Christopher Duggan for excellent technical support and acknowledge the support of the Medical Student Research Program (EAA and MAB), Louisiana State University Health Center in Shreveport, LA, USA.

\section{Disclosure}

The authors have no conflict of interest, no external funding, and no proprietary interest.

\section{References}

1. Chatterjee S, Quarcoopome CO, Apenteng A. Unusual type of epidemic conjunctivitis in Ghana. Br J Ophthalmol. 1970;54(9):628-630.

2. Lim KH, Yin-Murphy M. An epidemic of conjunctivitis in Singapore in 1970. Singapore Med J. 1971;12(5):247-249.

3. Kono R, Sasagawa A, Miyamura K, Tajiri E. Serologic characterization and sero-epidemiologic studies on acute hemorrhagic conjunctivitis (AHC) virus. Am J Epidemiol. 1975;101(5):444-457. 
4. Mirkovic RR, Schmidt NJ, Yin-Murphy M, Melnick JL. Enterovirus etiology of the 1970 Singapore epidemic of acute conjunctivitis. Intervirology. 1974;4(2):119-127.

5. Wolken SH. Acute hemorrhagic conjunctivitis. Surv Ophthalmol. 1974;19(2):71-84.

6. Sklar VE, Patriarca PA, Onorato IM, et al. Clinical findings and results of treatment in an outbreak of acute hemorrhagic conjunctivitis in southern Florida. Am J Ophthalmol. 1983;95(1):45-54.

7. Yin-Murphy M. Acute hemorrhagic conjunctivitis. Prog Med Virol. 1984;29:23-44.

8. Wright PW, Strauss GH, Langford MP. Acute hemorrhagic conjunctivitis. Am Fam Physician. 1992;45(1):173-178.

9. Lévêque N, Huguet P, Norder H, Chomel JJ. Enteroviruses responsible for acute hemorrhagic conjunctivitis. Med Mal Infect. 2010;40(4): 212-218.

10. Uchida Y, Ishii K, Miyamura K, Yamazaki S. Acute Hemorrhagic Conjunctivitis Etiology, Epidemiology, and Clinical Manifestations. Basel, Switzerland: Karger; 1989.

11. Tavares FN, Campos Rde M, Burlandy FM, et al. Molecular characterization and phylogenetic study of coxsackievirus A24v causing outbreaks of acute hemorrhagic conjunctivitis (AHC) in Brazil. PLoS One. 2011;6(8):e23206.

12. Lernout T, Maillard O, Boireaux S, Collet L, Filleul L. A large outbreak of conjunctivitis on Mayotte Island, France, February to May 2012. Euro Surveill. 2012;17(23):pii 20192.

13. Ayoub EA, Shafik CF, Gaynor AM, et al. A molecular investigative approach to an outbreak of acute hemorrhagic conjunctivitis in Egypt, October 2010. Virol J. 2013;10:96.

14. Centers for Disease Control and Prevention (CDC). Notes from the field: acute hemorrhagic conjunctivitis outbreaks caused by coxsackievirus A24v - Uganda and southern Sudan, 2010. MMWR Morb Mortal Wkly Rep. 2010;59(32):1024.

15. Shukla D, Kumar A, Srivastava S, Dhole TN. Molecular identification and phylogenetic study of coxsackievirus A24 variant isolated from an outbreak of acute hemorrhagic conjunctivitis in India in 2010. Arch Virol. 2013;158(3):679-684.

16. Aubry C, Gautret P, Nougairede A, et al. 2012 outbreak of acute hemorrhagic conjunctivitis in Indian Ocean islands: identification of Coxsackievirus A24 in a returned traveller. Euro Surveill. 2012;17(22):pii 20185.

17. Chansaenroj J, Vongpunsawad S, Puenpa J, et al. Epidemic outbreak of acute haemorrhagic conjunctivitis caused by coxsackievirus A24 in Thailand, 2014. Epidemiol Infect. 2015;31:1-7.

18. Harada K, Fujimoto T, Asato Y, Uchio E. Virological and epidemiological analysis of coxsackievirus A24 variant epidemic of acute hemorrhagic conjunctivitis in Okinawa, Japan, in 2011. Clin Ophthalmol. 2015;9:1085-1092.

19. Yan JY, Chen Y, Li Z, Gong LM, Lu YY, Zhang YJ. Study on the pathological and molecular characteristics of AHC epidemic in Zhejiang Province in 2010. Bing Du Xue Bao. 2011;27(5):421-426.

20. Yang J, Lin Y, Wang HY, et al. Identification and genetic characterization of coxsackievirus A24 isolated from patients with acute hemorrhagic conjunctivitis in Shandong Province. Bing Du Xue Bao. 2012;28(6): 663-669.

21. Srinivasa DK, D’Souza V. Economic aspects of an epidemic of haemorrhagic conjunctivitis in a rural community. J Epidemiol Community Health. 1987;41(1):79-81.

22. Chang $\mathrm{CH}$, Lin $\mathrm{KH}$, Anderson R. Towards an in vitro model for acute hemorrhagic conjunctivitis: cytokine-mediated vascular endothelial cell activation triggered by enterovirus type 70 infection. J Clin Virol. 2004;30(1):19-23.

23. Langford MP, Stanton GJ, Barber JC, Baron S. Early appearing antiviral activity in human tears during a case of picornavirus epidemic conjunctivitis. J Infect Dis. 1979;139(6):653-658.

24. Langford MP, Yin-Murphy M, Ho YM, Barber JC, Baron S, Stanton GJ. Human fibroblast interferon in tears of patients with picornavirus epidemic conjunctivitis. Infect Immun. 1980;29(3):995-998.
25. Langford MP, Barber JC, Sklar VE, et al. Virus-specific, early appearing neutralizing activity and interferon in tears of patients with acute hemorrhagic conjunctivitis. Curr Eye Res. 1985;4(3):233-239.

26. Yin-Murphy M, Abdul Rahim N, Phoon MC, Baharuddin-Ishak, Howe J. Early and rapid diagnosis of acute haemorrhagic conjunctivitis with tear specimens. Bull World Health Organ. 1985;63(4):705-709.

27. Stanton GJ, Langford MP, Baron S. Effect of interferon, elevated temperature, and cell type on replication of acute hemorrhagic conjunctivitis viruses. Infect Immun. 1977;18(2):370-376.

28. Langford MP, Kadi RM, Ganley JP, Yin-Murphy M. Inhibition of epidemic isolates of coxsackievirus type A 24 by recombinant and natural interferon alpha and interferon beta. Intervirology. 1988;29(6): 320-327.

29. Langford MP, Villarreal AL, Stanton GJ. Antibody and interferon act synergistically to inhibit enterovirus, adenovirus, and herpes simplex virus infection. Infect Immun. 1983;41(1):214-218.

30. Wadia NH, Wadia PN, Katrak SM, Misra VP. A study of the neurological disorder associated with acute haemorrhagic conjunctivitis due to enterovirus 70. J Neurol Neurosurg Psychiatry. 1983;46(7):599-610.

31. Dussart P, Cartet G, Huguet P, et al. Outbreak of acute hemorrhagic conjunctivitis in French Guiana and West Indies caused by coxsackievirus A24 variant: phylogenetic analysis reveals Asian import. J Med Virol. 2005;75(4):559-565.

32. Brandful JA, Takeda N, Yoshii T, et al. A study of the evolution of coxsackievirus A24 variant in Ghana by viral RNA fingerprinting analysis. Res Virol. 1991;142(1):57-65.

33. Takeda N, Tanimura M, Miyamura K. Molecular evolution of the major capsid protein VP1 of enterovirus 70. J Virol. 1994;68(2):854-862.

34. Lin KH, Chern CL, Chu PY, et al. Genetic analysis of recent Taiwanese isolates of a variant of coxsackievirus A24. J Med Virol. 2001;64(3): 269-274.

35. Pal SR, Kaiwar R, Prasad SR, Sarma AN, Gangwar DN, Jain IS. Evidence for recurrent infection and intra-familial spread of enterovirus-70 conjunctivitis during post-epidemic period. Indian J Med Res. 1985;81:241-246.

36. Pal SR, Szucs G, Melnick JL, et al. Immunofluorescence test for the epidemiological monitoring of acute haemorrhagic conjunctivitis cases. Bull World Health Organ. 1983;61(3):485-490.

37. Mathur A, Sharma B, Chaturvedi UC. The investigation of a recurrence of an AHC virus epidemic at Lucknow: a serosurvey for AHC virus antibodies before and after the epidemic. $J$ Hyg (Lond). 1977;79(2): 219-224.

38. Aoki K, Sawada H. Long-term observation of neutralization antibody after enterovirus 70 infection. Jpn J Ophthalmol. 1992;36(4):465-468.

39. Lin KH, Sheu MM, Huang L, et al. Seroepidemiological study of coxsackievirus type A24 variant (CA24v) in Taiwan. Gaoxiong Yi Xue Ke Xue Za Zhi. 1994;10(11):606-612.

40. Uchio E, Yamazaki K, Ishikawa H, et al. An epidemic of acute haemorrhagic conjunctivitis caused by enterovirus 70 in Okinawa, Japan, in 1994. Graefes Arch Clin Exp Ophthalmol. 1999;237(7):568-572.

41. Aoki K, Sawada H, Ishikawa H, Shimoji T, Kamada R. An outbreak of acute hemorrhagic conjunctivitis due to Coxsackie virus type A24 variant in Japan. Jpn J Ophthalmol. 1988;32(1):1-5.

42. Ogra PL, Karzon DT. Poliovirus antibody response in serum and nasal secretions following intranasal inoculation with inactivated poliovaccine. J Immunol. 1969;102:15-23.

43. Ogra PL. Mucosal immunity: some historical perspective on hostpathogen interactions and implications for mucosal vaccines. Immunol Cell Biol. 2003;81(1):23-33.

44. Bern C, Pallansch MA, Gary HE Jr, et al. Acute hemorrhagic conjunctivitis due to enterovirus 70 in American Samoa: serum-neutralizing antibodies and sex-specific protection. Am J Epidemiol. 1992;136(12): $1502-1506$

45. Chang WK, Liu KC, Foo TC, Lam MW, Chan CF. Acute haemorrhagic conjunctivitis in Hong Kong 1971-1975. Southeast Asian J Trop Med Public Health. 1977;8(1):1-6. 
46. Goh KT, Ooi PL, Miyamura K, Ogino T, Yamazaki S. Acute haemorrhagic conjunctivitis: seroepidemiology of coxsackievirus A24 variant and enterovirus 70 in Singapore. J Med Virol. 1990;31(3): 245-247.

47. van Bilsen $\mathrm{K}$, van Hagen PM, Bastiaans J, et al. The neonatal Fc receptor is expressed by human retinal pigment epithelial cells and is downregulated by tumour necrosis factor-alpha. Br J Ophthalmol. 2011;95(6): 864-868.

48. Hatch MH, Malison MD, Palmer EL. Isolation of enterovirus 70 from patients with acute hemorrhagic conjunctivitis in Key West, Florida. N Engl J Med. 1981;305(27):1648-1649.

49. Langford MP, Foreman BD, Srur L, Ganley JP, Redens TB. Bilateral acute pyogenic conjunctivitis with iritis induced by unilateral topical application of bacterial peptidoglycan muramyl dipeptide in adult rabbits. Exp Eye Res. 2013;116:324-336.

50. Langford MP, Robertson JB, Orillac R. Analysis of neutralizing antibodies to Enterovirus 70 and Coxsackievirus A24 variant, levels of immunoglobulins and total protein in tears of patients with acute hemorrhagic conjunctivitis. Ocul Immunol Inflamm. 1995;3(4):249-260.

51. Lamm ME. Current concepts in mucosal immunity. IV. How epithelial transport of IgA antibodies relates to host defense. Am J Physiol. 1998;274(4 pt 1):G614-G617.
52. Knop E, Knop N, Claus P. Local production of secretory $\operatorname{IgA}$ in the eye-associated lymphoid tissue (EALT) of the normal human ocular surface. Invest Ophthalmol Vis Sci. 2008;49(6):2322-2329.

53. Negro Ponzi A, Merlino C, Angeretti A, Penna R. Virus-specific polymeric immunoglobulin A antibodies in serum from patients with rubella, measles, varicella, and herpes zoster virus infections. J Clin Microbiol. 1985;22(4):505-509.

54. Corthésy B. Multi-faceted functions of secretory IgA at mucosal surfaces. Front Immunol. 2013;4:185.

55. Bidgood SR, Tam JC, McEwan WA, Mallery DL, James LC. Translocalized IgA mediates neutralization and stimulates innate immunity inside infected cells. Proc Natl Acad Sci U S A. 2014;111(37):13463-13468.

56. Muramatsu M, Yoshida R, Yokoyama A, et al. Comparison of antiviral activity between IgA and IgG specific to influenza virus hemagglutinin: increased potential of $\operatorname{IgA}$ for heterosubtypic immunity. PLoS One. 2014;9(1):e85582.

57. McClellan BH, Whitney CR, Newman LP, Allansmith MR. Immunoglobulins in tears. Am J Ophthalmol. 1973;76(1):89-101.

58. Brandtzaeg P. Induction of secretory immunity and memory at mucosal surfaces. Vaccine. 2007;25(30):5467-5484.

59. Sasagawa A, Kono R, Konno K. Laboratory-acquired infection of the eye with AHC virus. Jpn J Med Sci Biol. 1976;29(2):95-97.
Clinical Ophthalmology

\section{Publish your work in this journal}

Clinical Ophthalmology is an international, peer-reviewed journa covering all subspecialties within ophthalmology. Key topics include: Optometry; Visual science; Pharmacology and drug therapy in eye diseases; Basic Sciences; Primary and Secondary eye care; Patient Safety and Quality of Care Improvements. This journal is indexed on

Submit your manuscript here: http://www.dovepress.com/clinical-ophthalmology-journal

\section{Dovepress}

PubMed Central and CAS, and is the official journal of The Society of Clinical Ophthalmology (SCO). The manuscript management system is completely online and includes a very quick and fair peer-review system, which is all easy to use. Visit http://www.dovepress.com/ testimonials.php to read real quotes from published authors. 